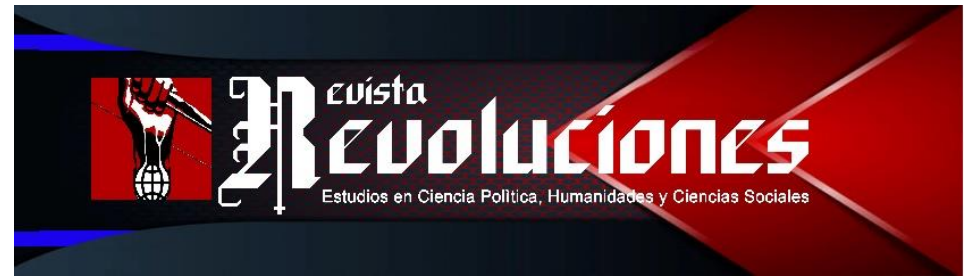

EDITORIAL

\title{
CUANDO LA MUERTE NOS MIRA CON DESEO DE LLEVARNOS AL TÁRTARO
}

\section{When death looks at us with a desire to take us to the tartarus}

\author{
Jesús Wiliam Huanca-Arohuanca ${ }^{1}$ \\ UNIVERSIDAD NACIONAL DE SAN AGUSTÍN DE AREQUIPA \\ PERÚ \\ jhuancaar@unsa.edu.pe \\ https://orcid.org/o0oo-0002-7353-1166
}

DOI: https://doi.org/10.35622/j.rr.2020.02.001

Recibido: 02-I-2020 / Aceptado: 28-V-2020 / Actualizado: 20-I-2021

\section{Resumen}

El planeta entero ha colapsado por el patógeno con denominación Covid-19, y la muerte protagonizó su mejor episodio de terror para llevar al tártaro a todos los que todavía no se daban cuenta de la vida que tenían. El presente tiene por objetivo reflexionar teóricamente las situaciones límite, las acciones funestas, las aparentes realidades, las patologías y los fenómenos devastadores que llevaron a la especie humana al borde de la extinción.

Palabras Clave: Muerte, coronavirus, aislamiento, vida, resistencia.

\begin{abstract}
The entire planet has collapsed by the Covid-19-named pathogen, and death starred in its best horror episode to bring to the Tatar all those who still did not realize the life they had.

\footnotetext{
${ }^{1}$ Filósofo político e investigador social en el departamento de Filosofía con mención en Ética y Filosofía Política por la Universidad Nacional de San Agustín de Arequipa [UNSA], Perú. Maestrante en la facultad de Ciencias Jurídicas en Derecho Procesal y Administración de Justicia por la Universidad Católica de Santa María [UCSM], Perú. Docente de la Especialidad de Ciencias Sociales y Sociólogo por la Universidad Nacional del Altiplano [UNA-P], Perú. En la actualidad dirige la Revista Revoluciones: Estudios en Ciencia Política, Humanidades y Sociales. Así mismo, es revisor de la Revista Educación y Sociedad de la Universidad de Ciego de Ávila Máximo Gómez Báez, Cuba y la Revista Innova Educación del Instituto Universitario de Investigación [INUDI], Perú. Líneas de investigación: Filosofía, Ciencia Política, Ciencias Sociales, Investigación, Políticas Educativas para el Desarrollo Sostenible y Sustentable, Historia Latinoamericana, Sociología y Gestión Pública. Impacto académico: tiene publicaciones a nivel internacional en Scopus, Web of Science y Scielo que recae en países como; Colombia, España, Ecuador, Venezuela, Costa Rica y Cuba; a nivel local tiene publicaciones en todas las regiones de la República Democrática del Perú.
} 
The present aims to theoretically reflect the limit situations, the dire actions, the apparent realities, pathologies and devastating phenomena that brought the human species to the brink of extinction.

Keyword: Death, coronavirus, isolation, life, endurance.

\section{INTRODUCCIÓN}

El tiempo resulta corto para los que tienen el enfermizo deseo de vivir más allá de un siglo, tal vez sea porque tienen todas las comodidades y oportunidades del cual siempre han alardeado. En cambio, otros desean vivir solo lo necesario, porque saben que el mundo en el cual viven es un infierno constructo de los que se creen dueños del mismo. Un planeta gobernado por humanos no humanos en su racionalidad y todo lo que concierne al fomento praxativo de la equidad, acompañado del plus de solidaridad del cual tanto habla el libro más leído y adorado de los últimos 2000 años, la Biblia y otros libros supuestamente sagrados, no existe. La especie humana aún no ha sido capaz de superar los problemas de siempre y al parecer tampoco ha encontrado el sentido y la forma de motivar a seguir con vida a los que desean lo contrario.

Teniendo todos lo problemas de orden mundial, a finales de 2019 llegó un virus maligno conocido por los expertos en virología como el "Coronavirus 2 del Síndrome Respiratorio Agudo Severo (SAR-CoV-2) generadora del COVID-19” (Huanca-Arohuanca, 2020a, p. 227). El virus fue tan letal, que toda la humanidad se rindió ante su imponente forma de viajar e infectar. No hubo nación alguna que pudiese contener eficientemente al patógeno ni expertos en ciencia capaz de crear el antídoto y la cura. En todas las naciones se vio que la muerte acechaba a la especie humana para llevarlos con él y que, si no cumplían los protocolos de bioseguridad, el tártaro sería su próxima parada.

\section{DESARROLLO}

El hecho de que la humanidad aún esté vivo en su mayoría y siga de pie, puede ser una de las grandes premisas del siglo XXI. La especie humana en su mayoría indigente, enfrentó cuerpo a cuerpo al satánico virus con sus propios medios ancestrales, a pesar de que necesitaron apoyo de sus respectivos actores gubernamentales, nunca tuvieron coherentemente una respuesta viable. Todos los centros de atención al paciente Covid-19 colapsaron sistemáticamente y el personal de salud fue impotente hacia esa enfermedad desconocida hasta la actualidad.

Solo la muerte como actor principal, llamaba a la puerta de los habitantes más desprotegidos por sus gobiernos para deleitarlos uno por uno, día por día y hombre por hombre, sin lugar a dudas, es el virus más letal que cualquier otro haya visto en el mundo después de la peste negra. Muchos creen que el maligno fue creado por las compañías farmacéuticas que 
monopolizan las instancias que tienen relación a la salubridad, otros juran desde la ideología judeo-cristiana, que el planeta valida la hipótesis del apocalipsis escrito en el Nuevo Testamento y para los que se creen dueños del mundo, la muerte es necesario, porque a través de esos acontecimientos se reduce a la humanidad sobrepoblada en su mayoría por los indigentes. La forma de pensar de los que viven cómodamente en aquel lugar fruto de la expoliación a sus semejantes, cae como la doctrina dominó cuando el sistema al que defienden no es capaz de garantizar la vida como máxima de cualquier sujeto.

Pasado el tiempo y para contener al maligno, se implantó casi en todas partes los mecanismos de cuarentena, toques de queda, cierre de fronteras y otras actividades de cúmulo poblacional. Sin embargo, los anteriores trajeron consigo la violación de los Derechos Humanos y la vulneración de las libertades. En esa caución, la preocupación y el temor a la muerte se hizo notorio y las irregularidades del sistema imperante se descubrieron más que nunca, porque hoy la gente que sufre los daños colaterales ya no es inerte a la realidad realizada en plena pandemia.

En consecuencia, una de las opciones que quedaba a la especie humana en momentos de una muerte evidente, es huir del hambre, de lo que fueron y de lo que serán, formando éxodos masivos, como si recordaran los pasajes bíblicos de la huida de Moisés hacia la tierra prometida. Pero sabían que ahora, no hay nada para ellos, más que miseria, exclusión y una enfermedad que espera ser contactado para habitar el cuerpo (Huanca-Arohuanca, 2019; 2020a; 202ob; 2020c; 2021; Huanca-Arohuanca \& Núñez, 2020; Huanca-Arohuanca \& Geldrech, 2020; Huanca-Arohuanca et al., 2020; Huanca-Arohuanca, Canaza-Choque, et al., 2020; Huanca-Arohuanca \& Pilco, 2021). Estaba claro, la muerte se preparaba para recibir el Oscar por la interpretación al mejor actor y por su amplia trayectoria de ser el encargado de llevar al tártaro a todas las víctimas por el Coronavirus.

No obstante, para los que habían tomado la opción de quedarse en el seno del hogar, no quedaba más que enfrentar al patógeno que entraba sin tocar la puerta. Todos y todas corrían por esconder y poner a buen recaudo su salud, pero nada era suficiente para lograr lo propuesto. Los hospitales colapsaron generando el dilema de la última cama al personal de salud, las compañías de salubridad solo se dedicaban a lucrar y a jugar con la salud de sus principales clientes, el infectado por Covid-19, y los aparatos estamentales del gobierno vivían escándalos de corrupción en un momento clave para la historia. Estaba claro, el destino final de todos era despertar en el averno.

Resulta increíble que hasta los países más poderosos del planeta se rindieran ante el maligno y que los organismos internacionales que lo acompañan como la Organización Mundial de la Salud se viera opacado y simplificado a un Puesto de Salud cualquiera. Al respecto existen teorías que indican la complicidad de los mismos para eliminar una buena porción de vida en el planeta. Cualquiera que vea lo que pasó y lo que sigue pasando, dirá que toda la humanidad está en peligro y que la bandera de paz ha sucumbido por los tiempos dialecticos movidos por el sistema patriarcal. 
Para los países emergentes y subalternos, el virus llegó como el desenlace fatalista de una novela denominado: neoliberalismo. Novela contada con falsedad para que la sumisión sea eficiente y que el aparente mundo feliz sea implantado en la conciencia de la gente más vulnerable. Por tanto, solo la historia fatídica de lo ya descrito llevará a comprender a los seres humanos que romper las barreras que limitan el libre albedrío cuando ven próximo su extinción, es la única manera para salir de la caverna que encadena al mundo aparente del que dibujaba Platón.

Sea cual fuese el destino de los habitantes del planeta, la muerte acompañado de una serie de enfermedades y anomalías inventados por los mismos hombres, seguirá conspirando contra la vida y la felicidad. La muerte siempre estará mirando de cerca todas las acciones que se realizan en vida, porque es el antítesis más peligroso de la existencia vital. No existe un eclecticismo de vivir para siempre, como no existe la certeza de cuánto tiempo se vivirá, ni síntesis que ponga una pausa entre el hecho de vivir o morir. Solo se sabe con seguridad que en cualquier momento moriremos e iremos al tártaro.

\section{CONCLUSIONES}

Algo muy interesante que ocurre a la especie humana, es que, a pesar de los estragos del Coronavirus, todos vuelven a la normalidad, muchos actúan como si no hubiese pasado nada, cuando todo pasó. Probablemente sea un mecanismo de defensa que, sin saber, es activado por el subconsciente de los que experimentaron la fatalidad, el terror y el óbito tenebroso del que nadie quiere ser parte. Sin embargo, el mecanismo en marcha no durará por mucho tiempo y develará muy pronto la real situación en el cual se encuentra la humanidad, es decir, nadie que esté vivo puede escapar a la inteligibilidad de los hechos pasado o futuros, todos se someten al final a una realidad objetiva.

Como reflexión definitoria, se debe aclarar que los seres humanos no caerán fácilmente ante el juego de la muerte, todos lucharán hasta el último tramo de sus días, puesto que, mantendrán como sea posible su vida. De manera que, el cliché fundamental a partir de año 2020 será: mientras se viva, la lucha continua y el pensar contrapoder es lo único que mantendrá latente a la vida humana bordeado por la muerte.

\section{REFERENCIAS BIBLIOGRÁFICAS}

Huanca-Arohuanca, J. W. (2019). El despertar de una nueva era: colonización y camino hacia la revolución. Revista Revoluciones, $1(1), \quad 1-3$. http://revistarevoluciones.com/index.php/rr/article/view/1/2

Huanca-Arohuanca, J. W. (2020a). Caleidoscopio social al Covid-19: pánico y desesperación en tiempos de aislamiento. Revista Universidad y Sociedad, 12(6), 226-231. https://rus.ucf.edu.cu/index.php/rus/article/view/1836

Huanca-Arohuanca, J. W. (2020b). Contrahegemonía y la lucha por la educación en el sur 
del Perú. Editorial Académica Española.

Huanca-Arohuanca, J. W. (2020c). Retropías y distopías de la educación en Puno. Revista Helios, 4(1), 270-271. https://doi.org/10.22497/Helios.41.4116

Huanca-Arohuanca, J. W. (2021). Narrativas de guerra y resistencia: participación de la mujer austral del Perú en la Guerra del Pacífico. Encuentros. Revista de Ciencias Humanas, Teoría Social y Pensamiento Crítico, 13, 50-59. https://doi.org/http://doi.org/10.5281/zenodo.4395218

Huanca-Arohuanca, J. W., Canaza-Choque, F. A., \& Flores, E. (2020). El dolor de los subalternos y el deseo de una revolución inconclusa: Narrativas sobre la violencia política en la Nación Aymara - Perú.Comuni@cción: Revista De Investigación En Comunicación $Y$ Desarrollo, 11(2), 177-189. https://doi.org/10.33595/22261478.11.2.436

Huanca-Arohuanca, J. W., \& Geldrech, P. (2020). Planificación educativa y gestión pedagógica-estratégica-operacional en las instituciones del nivel inicial en el sur del $\begin{array}{llll}\text { Perú. } & \text { Revista } & \text { 360 } & \text { 369-376), }\end{array}$ https://conrado.ucf.edu.cu/index.php/conrado/article/view/1497

Huanca-Arohuanca, J. W., \& Núñez, L. (2020). Estimaciones y contrastes de la pandemia en Perú y en el contexto mundial. Educare Et Comunicare. Revista Científica de La Fcultad de Humanidades, 8(2), 10-20. https://doi.org/10.35383/educare.v8i2.440

Huanca-Arohuanca, J. W., \& Pilco, N. (2021). Acciones revolucionarias en Ámérica Latina: Puno y el Alto Perú durante el proceso de independencia (1809-1825). Chakiñan. Revista de Ciencias Sociales y 14 Humanidades, https://doi.org/10.1590/SciELOPreprints.1364

Huanca-Arohuanca, J. W., Supo-Condori, F., Sucari, R., \& Supo, L. A. (2020). El problema social de la educación virtual universitaria en tiempos de pandemia, Perú. Revista Innovaciones Educativas, 22, 115-128. https://doi.org/10.22458/ie.v22iespecial.3218 